\title{
A meta-analysis on preschool evaluation researches in Taiwan
}

\author{
Lin, Hsiu Fen $\bigotimes$
}

Cultural Worker International Education, Taiwan, ROC (linshowfen@yahoo.com.tw)

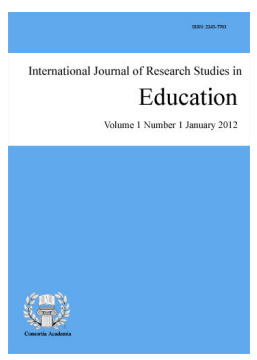

ISSN: $2243-7703$

Accepted: 20 September 2011 Online ISSN: 2243-7711

OPEN ACCESS

\section{Abstract}

The purpose of this paper is to undertake a meta-analysis on twenty (20) kindergarten and preschool researches. By analyzing its value, merits, demerits, and its implementation, this paper provide various suggestions for improvement of the kindergartens and preschools policy. By using the meta-analysis method to investigate related literature; content and document analysis was also applied to the various studies involved. Meta-analysis method is used to analyze the evaluation implementation situation for educational plans and projects in accordance with the educational evaluation standards. Results show that there is a need to integrate kindergartens and preschools in the future. Some suggestions include the establishment of correct evaluation concept and so as to enhance kindergarten and preschools' education through the application of a self-evaluation mechanism.

Keywords: preschool evaluation; meta-analysis; assessment; evaluation indicators; integration of kindergarten and preschool 


\section{A meta-analysis on preschool evaluation researches in Taiwan}

\section{Introduction}

Child care and education integration have become one of the important topics for the reform on current child care and education system in Taiwan. Such integration is said to involve strategies wherein counseling and evaluation of kindergartens and nursery schools will be executed by experts hired by local competent authority. Furthermore, this evaluation process are said to be executed by related professional institutes or organizations under the commission of local competent authority through the manner of outsourcing (Chou \& Chiang, 1995). Hence, in order to further analyze the inherent purpose and concept on such evaluations. This paper shall explore the outcomes of related studies on kindergartens and nursery schools evaluation with major regards to as a lesson to the policy of child care integration in the future while promoting educational evaluation work.

\section{Definition of terms}

Child care integration refers to merger of two systems or institutes; expecting to achieve integration and use of national resources, completing the early childhood care institutes, reacting to early childhood needs of modern society and family, providing child the same quality of early childhood care, and ensuring the fundamental rights and interests of early childhood educators. While, meta-evaluation refers to original procedure, method, activity, tool and data explanation, which is a process of judgment on values upon an in-depth analysis of pros and cons of known objects, plans and projects, with a purpose to ensure the quality of evaluation and to improve the implementation of evaluation task (Scriven, 1969, 1981; Stufflebeam, 1974).

Meta-analysis is said to be a statistical method of combining the results of a number of different studies in order to provide a larger sample size for evaluation and to produce a stronger conclusion than can be provided by any single study (Greenfacts, 2011). In addition, meta-analyses are attempted when previous studies were too small individually to achieve meaningful or statistically significant results. In essence, combining data from disparate groups is problematic, meta-analyses usually are considered more suggestive than definitive. The appeal of meta-analysis is that it in effect combines all the research on one topic into one large study with many participants. The danger is that in amalgamating a large set of different studies the construct definitions can become imprecise and the results difficult to interpret meaningfully.

\section{Evaluation in Taiwan}

An evaluation is to understand the situation of kindergartens and nursery schools in order to clarify the undetected situation of institute itself through a manner of external evaluation, to discover those kindergartens, nursery schools with a concern in teaching feature and child needs and to reward and to commend them accordingly (Chou \& Chiang, 1995). It also helps eliminate the flaws of those kindergartens, nursery schools that require operations improvement; the government shall aims to enable a complete ecology and development of child care quality upon the establishment of evaluation system.

In some other country, evaluation is also known as accreditation. In the United States, the term accreditation is most often used with reference to schools and hospitals. Accreditation of these institutions is performed by private nonprofit membership associations known as accrediting agencies. These agencies which are consist of private educational associations of regional or national scope; develops evaluation criteria and conduct peer evaluations to assess whether or not those criteria are met. Institutions and/or programs that request an agency's evaluation and that meet an agency's criteria are then accredited by that agency (DOE, 2008). In sum, accreditation is a system for recognizing educational institutions and professional programs for a level of performance, integrity and quality that entitles them to the confidence of the educational community and the 
public.

In Taiwan, the Taiwan Accreditation Foundation (TAF) is the only national accreditation body in Taiwan. TAF accreditation recognizes and promotes organizations by assessing, against international standards and criteria, their competence in providing specific types of certification, calibration, testing, inspection and proficiency testing programmed services (TAF, 2011). TAF is more focused on the industry, while the Higher Education Evaluation and Accreditation Council of Taiwan (HEEACT) is more on education (HEEACT, 2008). However, still the evaluation mechanism in the educational institutions of Taiwan is controlled by the Ministry of Education. The table below shows the evaluation system in kindergarten and preschool education.

Table 1

Evaluation system in kindergarten and preschool education

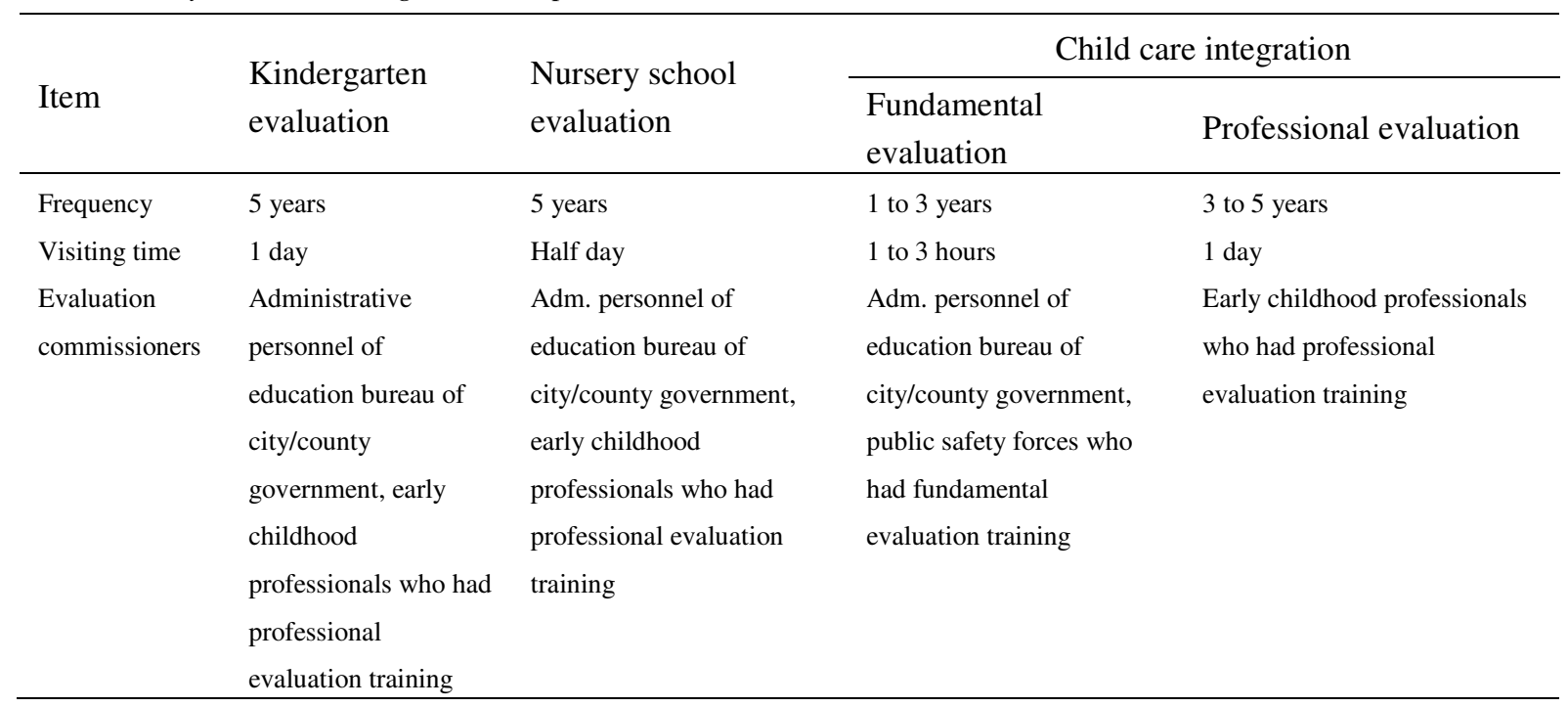

\section{Methodology}

The study followed a paradigm which is the concept of input processes and output analyses. Figure 3 shows the research framework.

\begin{tabular}{|l|l|l|}
\hline Basic information of evaluation & \multicolumn{1}{|c|}{ Child care integration evaluation } \\
\hline study & & Evaluation criteria: \\
Year conducted & a. & Purpose \\
Research objectives & b. & Content \\
Research objectives standard & c. & Procedure \\
Research conclusions & d. & Model \\
Suggestions & e. & Results \\
\hline
\end{tabular}

Figure 3. Research framework 


\subsection{Research participants}

The meta-analyses involved 20 studies done from 1996 to 2007. Table 2 shows the list of the studies.

\section{Table 2}

List of studies reviewed

\begin{tabular}{|c|c|c|c|}
\hline & Author/s & Year & Title of study \\
\hline 1. & Lee, M. C. & 1996 & $\begin{array}{l}\text { A study of kindergarten evaluation from the perspective of kindergarten } \\
\text { principals in Taipei city }\end{array}$ \\
\hline 2. & Hsu, H. Q. & 2001 & A study of self evaluation by kindergartens \\
\hline 3. & Chen, Y. C. & 2002 & $\begin{array}{l}\text { A process of kindergarten's participation in counseling evaluation plan - A } \\
\text { case study of } 4 \text { kindergartens in Taipei city }\end{array}$ \\
\hline 4. & $\mathrm{Su}, \mathrm{H} . \mathrm{W}$. & 2002 & A study of meta-evaluation by the kindergartens in Taipei city \\
\hline 5 . & Chen, H. C. & 2003 & $\begin{array}{l}\text { A study of evaluation plan implementation of kindergarten counseling in } \\
\text { Taipei county: A case study of school year } 2001\end{array}$ \\
\hline 6. & Huang. L. C. & 2003 & $\begin{array}{l}\text { Establishment of evaluation plan for the specific competence of kindergarten } \\
\text { teachers }\end{array}$ \\
\hline 7. & Ji, Y. F. & 2003 & $\begin{array}{l}\text { Establishment of evaluation index for child welfare institutions-nursery } \\
\text { schools in Taichung county as a case study }\end{array}$ \\
\hline 8. & Chang, L. Y. & 2004 & $\begin{array}{l}\text { A study of implementation status of kindergarten evaluation - An evaluation } \\
\text { of preschool education administration in Tainan county }\end{array}$ \\
\hline 9. & Chiang, L. L. & 2004 & An evaluation plan for kindergarten counseling in Taipei county \\
\hline 10. & Tsao, R. C. & 2004 & A study of meta-evaluation for the kindergartens in Taoyuan county \\
\hline 11. & Chang, S. H. & 2005 & A study of meta-evaluation for private kindergartens in Taoyuan county \\
\hline 12. & Huang, Y. F. & 2005 & $\begin{array}{l}\text { A study of evaluation index for kindergarten's operation efficiency-DEA } \\
\text { evaluation mode }\end{array}$ \\
\hline 13. & Liang, A. C. & 2005 & $\begin{array}{l}\text { A case study on the evaluation of child care institutions-public school in } \\
\text { Tainan county }\end{array}$ \\
\hline 14. & Pan, Y. H. & 2005 & A meta-evaluation study of kindergarten evaluation in Kaohsiung city \\
\hline 15 . & Wu, C. Y. & 2005 & Establishment of training plan for kindergarten evaluation commissioner \\
\hline 16. & Chao, K. L. & 2006 & A meta-evaluation study of kindergarten evaluation in Kaohsiung city \\
\hline 17. & Chen, F. L. & 2006 & $\begin{array}{l}\text { An analysis of kindergarten evaluation system in Taiwan-Taipei city as a } \\
\text { case study }\end{array}$ \\
\hline 18. & Lee, X. Y. & 2006 & An evaluation plan for the kindergartens in - A perspective of commissioner \\
\hline 19. & Lin, H. F. & 2007 & Related studies of meta-evaluation for the nursery schools in Taipei \\
\hline 20. & Lo, Y. Y. & 2007 & A study of early childhood educators' viewpoints on kindergarten evaluation \\
\hline
\end{tabular}

Note. Studies are written in Mandarin Chinese

\section{Results and conclusions}

The current conclusions and suggestions of the research outcomes can be provided as a reference to evaluation system after integration of child care in the future. These are as follows:

1. There are more studies on meta-evaluation of kindergartens and less for nursery schools. 
2. Targeting 6 cities/counties only has led to a failure in understanding the evaluation status of other cities/counties.

3. The direction of research under discussion lacks participation of government units, evaluation commissioners and parents.

4. Evaluation tools and contents were mentioned the most while self evaluation was mentioned the least in the conclusions.

5. Those satisfactory evaluation items cover:

$>$ An index of early childhood quality reports a power of prediction on service performance.

$>$ The pre-counseling, self evaluation, visit evaluation, follow-up evaluation are in moderate order and in compliance with the logic.

$>$ A top appraisal is rendered in terms of efficacy perspective

$>$ The commissioners were recognized by their area of expertise and evaluation procedure.

> Appropriate categorization of evaluation contents.

6. The evaluation items to be improved include the following:

$>$ Insufficient flexibility of evaluation manual.

$>$ Individual differences were not taken into consideration.

$>$ Insufficient self evaluation and visiting time.

> A specialized evaluation institute is not established.

$>$ Establish license system for counseling and evaluation manpower.

$>$ Diverse use of counseling/evaluation outcomes.

$>$ Evaluation on public/private sectors should be separated.

$>$ Reinforce regular subsequent counseling measures and promotion of evaluation task concept.

\section{Recommendations and implications}

The current analysis provided the following overall evaluations, such as:

1. Practical planning of evaluation, the evaluation contents should reflect the value of evaluation.

2. Increase time for self evaluation processing.

3. Provide subsequent evaluation and necessary assistance upon evaluation outcomes.

4. Increase studies of evaluation index.

5. Increase studies with regard to evaluation time.

6. Enhance consistent reliability of the appraiser.

7. The pre-education organizations which report poor evaluation outcome should subject to follow-up counseling. 
Lin, H. F.

While also providing numerous suggestions to evaluation plans for child care integration, such as:

1. Establish accurate idea about evaluation to truly enhance the quality of kindergarten through self evaluation mechanism.

2. Establish specialized unit or specialized person for evaluation task processing.

3. Way to announce the evaluation outcome should be diversified.

4. A well interaction process that combines counseling and evaluation.

5. Respect difference between kindergartens; introduce both qualitative and quantitative research for evaluation items.

Some suggestions to be considered are as such:

1. Add evaluation index, evaluation time and process, professional index of evaluation commissioners and related studies.

2. Research objects will reach stakeholders of child care integration plans to reinforce inference ability of the study.

3. Promote the education of correct concept of kindergarten and preschool evaluation.

4. Set up an exclusively independent unit or personnel to take charge the evaluation work.

5. Use multiple ways of announcing the evaluation results.

6. The evaluation results should meet the evaluation principle, appropriate reward should be applied.

7. Perform a benign interaction process by combining both counseling and evaluation.

8. Respect the differences among kindergartens and preschools. 


\section{References:}

Chang, S. H. (2005). A study of meta-evaluation for private kindergartens in Taoyuan county [In Chinese]. Unpublished masteral thesis, Chung Yuan Christian University, Taoyuan, Taiwan.

Chang, L. Y. (2004). A study of implementation status of kindergarten evaluation - An evaluation of preschool education administration in Tainan county [In Chinese]. Unpublished masteral thesis, National Chiayi University, Tainan, Taiwan.

Chao, K. L. (2006). A meta-evaluation study of kindergarten evaluation in Kaohsiung city [In Chinese]. Unpublished doctoral dissertation, National Tainan University, Tainan, Taiwan.

Chen, F. L. (2006). An analysis of kindergarten evaluation system in Taiwan-Taipei city as a case study [In Chinese]. Unpublished masteral thesis, Taipei Municipal University of Education, Taipei, Taiwan.

Chen, H. C. (2003). A study of evaluation plan implementation of kindergarten counseling in Taipei county: A case study of school year 2001 [In Chinese]. Unpublished masteral thesis, National Hsinchu University of Education, Hsinchu, Taiwan.

Chen, Y. C. (2002). A process of kindergarten's participation in counseling evaluation plan - A case study of 4 kindergartens in Taipei city [In Chinese]. Unpublished masteral thesis, National Hsinchu University of Education, Hsinchu, Taiwan.

Chiang, L. L. (2004). An evaluation plan for kindergarten counseling in Taipei county [In Chinese]. Preschool education information, 136, 15-23.

Chou, S. H., \& Chiang, L. L. (1995). The evaluation system of kindergarten in Taiwan. Reported by the chief editor of the Chinese Society of Education [In Chinese], Education Evaluation, 327-357.

DOE. (2008). Accreditation in the United States. Retrieved January 20, 2008, from http://www.ed.gov/admins/finaid/accred/accreditation.html\#Overview

Greenfacts. (2011). Meta-analyses. Retrieved August 1, 2011, from http://www.greenfacts.org/glossary/mno/meta-analysis.htm

HEEACT. (2008). About HEEACT. Retrieved August 1, 2011, from http://www.heeact.edu.tw/ct.asp?xItem $=1092 \& \mathrm{CtNode}=444 \& \mathrm{mp}=4$

Hsu, H. Q. (2001). A study of self evaluation by kindergartens [In Chinese]. Unpublished masteral thesis, Taipei Municipal University of Education, Taipei, Taiwan.

Huang. L. C. (2003). Establishment of evaluation plan for the specific competence of kindergarten teachers [In Chinese]. Unpublished masteral thesis, National Hsinchu University of Education, Hsinchu, Taiwan.

Huang, Y. F. (2005). A study of evaluation index for kindergarten's operation efficiency-DEA evaluation model [In Chinese]. Unpublished masteral thesis, Chang Jung Christian University, Taipei, Taiwan.

Ji, Y. F. (2003). Establishment of evaluation index for child welfare institutions-nursery schools in Taichung county as a case study [In Chinese]. Unpublished masteral thesis, Nan Hua University, Taichung, Taiwan.

Liang, A. C. (2005). A case study on the evaluation of child care institutions-public school in Tainan county [In Chinese]. Unpublished masteral thesis, National Chengchi University, Taipei, Taiwan.

Lee, M. C. (1996). A study of kindergarten evaluation from the perspective of kindergarten principals in Taipei city [In Chinese]. Unpublished masteral thesis, Chinese Culture University, Taipei, Taiwan.

Lee, X. Y. (2006). An evaluation plan for the kindergartens in - A perspective of commissioner [In Chinese]. Unpublished master thesis, National Hsinchu University of Education, Hsinchu, Taiwan.

Lin, H. F. (2007). Related studies of meta-evaluation for the nursery schools in Taipei [In Chinese]. Unpublished study, Kang-Ning Junior College of Medical Care and Management, Taipei city.

Lo, Y. Y. (2007). A study of early childhood educators' viewpoints on kindergarten evaluation [In Chinese]. Unpublished masteral thesis, National Pingtung University of Science, Pintung, Taiwan.

Pan, Y. H. (2005). A meta-evaluation study of kindergarten evaluation in Kaohsiung city [In Chinese]. Unpublished masteral thesis, National Pingtung University of Science, Pintung, Taiwan. 
Lin, H. F.

Scriven, M. (1969). An Introduction to meta-evaluation. Educational products Report, 2(5), 36-38.

Scriven, M. (1981). Evaluation thesaurus. Newbury Park, CA: Edge Press.

Stufflebeam, D. L. (1974). Meta-evaluation. Occasional Paper Series, No. 3. Kalamazoo, MI: Western Michigan University Evaluation Center.

$\mathrm{Su}, \mathrm{H}$. W. (2002). A study of meta-evaluation by the kindergartens in Taipei city [In Chinese]. Unpublished masteral thesis, Taipei Municipal University of Education., Taipei, Taiwan.

TAF. (2011). About TAF. Retrieved August 15, 2011, from http://www.cnla.org.tw/tafweb/indexEng.aspx

Tsao, R. C. (2004). A study of meta-evaluation for the kindergartens in Taoyuan county [In Chinese]. Unpublished masteral thesis, National Taipei University of Education, Taipei, Taiwan.

Wu, C. Y. (2005). Establishment of training plan for kindergarten evaluation commissioner [In Chinese]. Unpublished masteral thesis, National Hsinchu University of Education, Hsinchu, Taiwan. 